\title{
Effect of Load Frequency and Amplitude of Displacement on Soft Rock Joints under Cyclic Shear loads
}

\section{S.M.Mahdi Niktabar ( $\nabla$ mahdi.niktabar@ugn.cas.cz )}

ÚGN AV ČR: Ustav geoniky Akademie ved Ceske republiky https://orcid.org/0000-0002-1723-3375

\section{K. Seshagiri Rao}

Indian Institute of Technology Delhi

\section{Amit Kumar Shrivastava}

Delhi Technological University

\section{Jiřr Ščučka}

ÚGN AV ČR: Ustav geoniky Akademie ved Ceske republiky

\section{Research Article}

Keywords: Rock joints, Cyclic shear load, Frequency of load, Displacement amplitude, Shear mechanism

Posted Date: February 11th, 2022

DOI: https://doi.org/10.21203/rs.3.rs-1256859/v1

License: (c) This work is licensed under a Creative Commons Attribution 4.0 International License.

Read Full License 


\title{
Effect of Load Frequency and Amplitude of Displacement on Soft Rock Joints under Cyclic
}

\section{Shear loads}

S. M. Mahdi Niktabar ${ }^{1, *}$, K. Seshagiri Rao ${ }^{2}$, Amit Kumar Shrivastava $^{3}$, Jiři Ščučka $^{1}$

${ }^{1}$ Department of Laboratory Research on Geomaterials, Institute of Geonics of the Czech Academy of Sciences, Ostrava, Czech Republic

${ }^{2}$ Department of Civil Engineering, Indian Institute of Technology Delhi, India

${ }^{3}$ Department of Civil Engineering, Delhi Technological University, India

\section{Acknowledgments:}

The financial support from Indian Institute of Technology Delhi is greatly appreciated

\begin{abstract}
A series of cyclic shear tests was conducted on soft synthetic rock joints with $30^{\circ}-30^{\circ}$ asperities. Large scale shear apparatus was used in the experiments to investigate effects of shear load frequency and amplitude of displacement on the joint behaviour. Varying load frequencies $(0.01$, 0.05 and $0.1 \mathrm{~Hz}$,$) and displacement amplitudes ( \pm 4, \pm 6$, and $\pm 8 \mathrm{~mm})$ for three different normal stresses $(0.1,0.5$ and $1 \mathrm{MPa})$ were applied. The results indicated that the first peak shear stress on the joint is significantly influenced by the frequency of cyclic shear load and subsequent peaks of shear stress are largely influenced by the amplitude of displacement. Reduction in peak shear stress at higher frequency of load is greater than the reduction at lower frequency of load under cyclic movements. Shear mechanism on the joint asperities at low normal stress demonstrate asperity diminishing does not depend on load direction at high frequency. Whereas,
\end{abstract}

*Corresponding Author

1. Department of laboratory research on geomaterials, Institute of Geonics of the Czech Academy of Sciences, Czech Republic, Ostrava

Email address: Mahdi.Niktabar@ugn.cas.cz

Postal address: Studentska 1768, 70800 Ostrava-Poruba, 
at low frequency of loads, it depends on direction of starting cyclic shear load. Low amplitude of displacement has no effect on asperity deformation under cyclic loads. As the amplitude rises, the diminishing of asperities increases significantly. Shear mechanism and asperity diminishing at low normal stress is similar for the both higher amplitude of displacement and lower frequency of load. Comparison of shear strength envelopes indicated an opposite behaviour of the joint at varying load frequencies and displacement amplitudes.

Key words: Rock joints; Cyclic shear load; Frequency of load; Displacement amplitude; Shear mechanism;

\section{Introduction}

Earthquakes and other seismic activities (due to excavation in mining or underground structures) distribute dynamic loads on rock masses. These dynamic loads can lead to number of cyclic shear movements with different frequencies and amplitudes of displacement along the joints in the rock mass. Hence, shear resistance of the joints can change under cyclic loads and affect the rock mass stability. Study of cyclic shear behaviour of jointed rocks under different dynamic parameters plays an important role for analysis, design and safety of rock structures.

Shear behaviour of rock joints was investigated with different shear velocity under monotonic loads. Results of experiments indicate that shear resistance increases with increasing shear velocity (Schneider 1977; Gillette et al. 1983; Barla et al. 1990; Barbero et al. 1996 and Hencher 1981). However, other results show that shear resistance decreases with increasing shear velocity (Jafari et al. 2003; Mirzaghorbanali et al. 2014; Tang et al. 2016). No velocity dependency was reported by Hassani and Scoble (1985) for shear resistance in sandstone $(0.012-0.180 \mathrm{~mm} / \mathrm{min})$. 
Crawford and Curran (1981) and Atapour and Moosavi (2014) observed different shear behaviour on natural and artificial joints in soft and hard rocks. The results indicate that the shear resistance of real joint increases with increasing shear velocity on soft rocks (up to critical shear displacement rate) but it declines for hard rocks. However, the opposite shear behaviour was observed for artificial joints. Thus, the shear resistance under different shear velocity is probably influenced by the type of rocks and joints.

Most studies on cyclic shear loads were conducted under constant frequency and amplitude of displacement as presented by Hutson and Dowding (1990), Qiu et al. (1993), Huang et al. (1993), Jing et al. (1993), Homand-Etienne et al. (1999), Lee et al. (2001), Ferrero et al. (2010), Nemcik et al. (2013), and Niktabar et al. (2017). As the seismic events can occur at different distances from the rock mass, it is also necessary to study the behaviour of rock joints at different shear load frequencies and amplitudes of displacement (Ramulu et al. 2009, Yang et al. 2019 and Gomez et al. 2020).

Variation of shear displacement on rock joints under cyclic load was investigated by Jafari et al. (2003). They observed second-order asperities were demolished on rock joints with low amplitude of displacement. At high loading amplitude both first and second-order asperities diminished. Similar joint degradation was observed by Ferrero et al. (2010). Damage of joint asperities at lower shear amplitudes was smaller compared to the higher amplitudes. Nguyen (2013) studied the behaviour of jointed rocks under cyclic shear loading with different frequencies (dynamic condition). The results show that the peak shear stress under this condition is $30 \%$ greater than that under static condition. Nemcik et al. (2013) investigated influence of initial normal stress and number of shear cycles on the joints under constant normal stiffness. Results indicate that with increasing initial normal stress, the influence of shear rate is not 
significant under this condition. Insignificant effect of shear rate on peak shear stress with increasing number of cycles was observed. The shear stress, normal stress and normal displacement for rock joints (infilled) under constant normal stiffness was increased with increasing shear rate as presented by Guansheng et al. (2020). Wu et al. (2019) conducted cyclic shear load on bolted rock joints for small and large displacements. When displacement was large; the shear strength reduction of bolted joints was comparable to the unbolted joint. However, for small displacement, the rock bolt had minor effect on the shear strengths.

Soft rock joints or weathered joints usually have a low shear resistance (Richards 1975; Barton and Choubey 1977; Dearman 1978; Ram and Basu 2019) and it is the main reason of rock mass failure (Nkpadobi 2015; Yan et. al 2019). Regarding cyclic shear loads, deterioration of joint asperities is faster as the number of cycle increases. Hence, in this study a series of cyclic shear tests was conducted on simulated soft rock joints with varying load frequency and amplitude of displacement to investigate effects of these dynamic parameters on shear behaviour of the joints. There is a lack of information in shear mechanism on soft (or weathered) rock joints under cyclic shear loads.

\section{Experimental Methodology}

\subsection{Preparation of Specimens}

In order to model soft rock or weathered joints, plaster of Paris has been selected as model material. The test specimens with synthetic joints were prepared by casting the plaster into special steel moulds. The plaster paste with water-powder ratio of 0.6 was mixed for 2 minutes and then poured into the moulds with inside dimensions of $299 \times 299 \times 85 \mathrm{~mm}$, placed on a vibrating table. An aluminium plate with $30^{\circ}-30^{\circ}$ asperity was placed on the bottom of each mould before pouring the paste. Inside of the mould and surface of the asperity plate were 
lubricated with oil for easy removal of the specimen without breaking the asperities. The paste in the moulds was vibrated for 30 seconds to remove the air bubbles from the material (Fig. 1a). The hardened specimens were removed from the moulds after 60 minutes and then left for 20 days at laboratory temperature for the air curing (Fig. 1b). The test specimens with joint asperity angles of $30^{\circ}-30^{\circ}$ were formed.The hardened plaster, having the uniaxial compressive strength of $6 \mathrm{MPa}$, is suitable for simulating the mechanical behaviour of joints in weathered or soft rocks like siltstone, claystone, shale, coal and rock salt. Tangent modulus, Poisson ratio, cohesion and intact friction angle of specimens are $2.45 \mathrm{GPa}, 0.27,0.72 \mathrm{MPa}$ and $51.3^{\circ}$ respectively.

\section{Fig. 1 [Near here]}

\subsection{Shear Machine and Testing Procedure}

Automatic static and cyclic shear testing machine (Niktabar et al. 2018) was utilized in this experiments (Fig. 2). The shear machine is a large scale apparatus and it is combination of the four main units, including frame and loading unit (1), hydraulic power pack (2), data acquisition (3), and cooling unit (4). The size of each shear box is $300 \mathrm{~mm} \times 300 \mathrm{~mm} \times 448 \mathrm{~mm}$. Maximum capacities of normal and horizontal load cells are $500 \mathrm{kN}$ and $1000 \mathrm{kN}$, respectively. Calibration of the load cells and linear variation displacement transducers (LVTD) was conducted before the experiment. Software automatically collects data during the shear loading. This apparatus has capability to carry out cyclic shear tests (Fig. 3 ) on jointed rocks under different frequencies $\left(f_{\mathrm{s}}\right)$ and displacement amplitudes $\left(\mathrm{a}_{\mathrm{s}}\right)$.

A series of cyclic shear tests were performed on soft rock joints under varying frequencies $(0.01$, 0.05 and $0.1 \mathrm{~Hz})$ by keeping amplitude of displacement constant $( \pm 8 \mathrm{~mm})$. Another series of tests were conducted under varying displacement amplitudes $( \pm 4, \pm 6$ and $\pm 8 \mathrm{~mm})$ while keeping frequency of shear loads constant $(0.01 \mathrm{~Hz})$. Three different normal stresses $(\mathrm{P}=0.1,0.5$ and 1 MPa) and thirty shear loading cycles were applied for each shear test. The tests were conducted 
based on shear displacement control and constant normal load condition (normal stiffness was kept zero). Shear test parameters are presented in Table 1.

\section{Fig. 2 and Fig. 3 [Near here]}

\section{Table 1 [Near here]}

\section{Results and Discussion}

\subsection{Effect of Cyclic Shear Load Frequency on the Joint}

Test results for different shear load frequencies at the normal stress of $0.1 \mathrm{MPa}$ are presented in Fig. 4. The graphs show shear stress and normal displacement (dilation) vs. horizontal displacement. With increasing frequency of cyclic shear load from $0.01 \mathrm{~Hz}$ to $0.05 \mathrm{~Hz}$, first peak shear stress of the joint was increased from 0.34 MPa to 0.42 $\mathrm{MPa}$ (23\%). When frequency increased from $0.01 \mathrm{~Hz}$ to $0.1 \mathrm{~Hz}$, peak shear stress increased from $0.34 \mathrm{MPa}$ to $0.48 \mathrm{MPa}(41 \%)$ (Table 2; Fig. 4a, b, c), i.e. shear strength on the joints increases with rising shear load frequency. However, with increasing number of cycles $(\mathrm{N}>2)$, the influence of frequency was insignificant on the joint (Fig. 6a, b, and c). The maximum difference of peak shear stress was observed between the first and the second cycles (Table 2). With increasing frequency of shear load, the difference of peak shear stress between the first and the last cycle ( $\mathrm{N}=30)$ increased. It was 59\%, $64 \%$ and $67 \%$ for shear frequencies of $0.01,0.05$ and $0.1 \mathrm{~Hz}$ respectively (Table 2). These results demonstrate that the reduction of shear strength at higher frequency $(0.1 \mathrm{~Hz})$ was greater than the reduction at lower frequency $(0.01 \mathrm{~Hz})$ under cyclic movements (Fig. 6a, b, and c).

Angle of slope for the post peak shear stress increases (negatively) as the load frequency increases. It is clear for the first cycle (Fig. 4a, b, c; Fig.13a, b, c in appendix), but it was not observed for subsequent cycles.

Joint with low shear frequency $(0.01 \mathrm{~Hz})$ was under compression (positive normal displacement) after several cycles (Fig. 4d). But joint with high frequency of shear load $(0.1 \mathrm{~Hz})$ could dilate 
(negative normal displacement) even at the last cycle (Fig. 4f), i.e. compression of joint asperities was more significant at lower shear frequency under cyclic loads.

Peak dilation of the joint vs. number of cycles for different shear load frequencies is illustrated in Fig. 7a, b, c. For low frequency $(0.01 \mathrm{~Hz})$, the peak joint dilation at forward movement $(+8 \mathrm{~mm})$ was higher than at backward movement $(-8 \mathrm{~mm})$ for the first cycle. This difference was $33.4 \%$ (Fig. 7a). However, the difference of peak joint dilation between forward and backward movements decreases gradually and it was equal after several cycles $(\mathrm{N}=22)$.

Fig. 4[Near here]

Table 2 [Near here]

With increasing frequency of cyclic shear load to 0.05 and $0.1 \mathrm{~Hz}$, the difference of peak joint dilation between forward and backward movements was decreased to $20.1 \%$ and $1.2 \%$ for the first cycle (Fig. 7b and c). With increasing frequency of shear load, peak joint dilation between forward and backward movements became equal for the first cycle (Fig. 7c). As the number of cycles increased, the peak dilation decreased with the same rate for the both movements. This joint behaviour shows that the shear mechanism is different at high and low frequency of cyclic loads. Asperity diminishing on the both slopes was equal at high frequency of load (Fig. 8b), because there was no sufficient time to deform second slopes of the asperities. Hence, the peak dilation was the same in the both forward and backward movement. At low frequency of load, asperity diminishing on the both slopes was unequal (Fig. 8a), because there was a sufficient time to deform second slopes of the asperities (significant deformation was observed during the backward movements). Therefore, the peak dilation was different in forward and backward movements. It can be stated that the shear mechanism on the joint at high load frequency does not depend on load direction. However, at low frequency, the shear mechanism depends on direction of starting movement of cyclic load. As the normal stress increases $(0.5$ and $1 \mathrm{MPa})$ on 
the joint, the joint behaviour has changed due to significant degradation of asperities at the first cycle (Figs. 12 and 13 in appendix). After few cycles, the joint behvaiour was same as a planar joint behaviour because of complete demolishing of asperities.

\subsection{Effect of Cyclic Shear Displacement on the Joint}

Shear test results for different amplitude of displacement at the normal stress of $0.1 \mathrm{MPa}$ are presented in Fig. 5. The graphs show shear stress and normal displacement (dilation) vs. horizontal displacement. Peak shear stress on the joint was constant as the number of shear cycles increased for amplitude of $\pm 4 \mathrm{~mm}$ (Fig. 5a), i.e. number of cycles was not effective on peak shear stress at low level of amplitude (Table 3). With increasing displacement amplitude to $\pm 6 \mathrm{~mm}$ (Fig. 5b), peak shear stress started to decrease as the number of shear cycles increased. This reduction for peak shear stress was more significant when shear amplitude was $\pm 8 \mathrm{~mm}$ (Fig. 5c). The peak shear stress decreased by $33 \%$ and $57 \%$ for $\pm 6 \mathrm{~mm}$ and $\pm 8 \mathrm{~mm}$ amplitudes at thirty cycles.

\section{Fig. 5[Near here]}

\section{Table 3 [Near here]}

Peak shear stress vs. number of cycles is demonstrated for different amplitudes of displacement in Fig.6d, e and f. The peak shear stress was equal for varying shear amplitudes at the first cycle $(\mathrm{N}=1)$, but it was different for subsequent cycles.Joint was under compression at low shear amplitude $( \pm 4 \mathrm{~mm})$ during all cycles (Fig.5d). When the amplitude increased $( \pm 6$ and $\pm 8 \mathrm{~mm})$, significant dilation was observed on the joint (Fig. 5e and f). Due to diminishing of asperities, this dilation was declined as the number of cycles increased.

\section{Fig. 6 and Fig. 7 [Near here]}

Comparison between the graphs in Fig. 6 shows that frequency of load (Fig. 6a, b and c) has significant effect on the first peak shear stress. However, for different displacement amplitudes 
(Fig. 6d, e and f), the first peak shear stress was similar and significant difference of peak shear stress was observed for subsequent cycles.

Peak joint dilation vs. number of cycles for different displacement amplitude is demonstrated in Fig. 7 (d, e and f). According to the graphs, peak dilation values at forward and backward movements are equal at low displacement amplitude $( \pm 4 \mathrm{~mm}$; Fig. $7 \mathrm{~d})$ for thirty cycles. With increasing amplitude $( \pm 6 \mathrm{~mm})$ the difference of peak dilation between both movements appeared and it was $14.9 \%$ for the first cycle (Fig. 7e). For the amplitude of $\pm 8 \mathrm{~mm}$, the difference of peak dilation was increased by $33.4 \%$ for the same cycle. This difference decreases gradually with increasing number of cycles (Fig. 7f).

Shear mechanism at low displacement amplitude was sliding only (Fig. 9a) without diminishing the asperities; hence, direction of movements (forward or backward) has no effect on asperities degradation. However, at high amplitude $( \pm 8 \mathrm{~mm})$, the shear mechanism depends on direction of starting movement of cyclic load (Fig. 9b). Asperity diminishing for high displacement amplitude was significant in the second slope of asperity which was involved in the cyclic shear. Shear mechanism and asperity diminishing were similar for the both higher amplitude of displacement (Fig. 9b) and lower frequency of load (Fig. 8a). It is because of grater diminishing on the second slopes of asperities during cyclic movements. Hence, failure on rock joint is more expected in opposite to the direction of starting movement of cyclic load.

\section{Fig. 8 and Fig. 9 [Near here]}

Specimens were removed from the shear box to observe the effect of displacement amplitude $( \pm 4, \pm 6$ and $\pm 8 \mathrm{~mm}$ ) on the joint surface (Fig. 10). In case of joint with low displacement amplitude $( \pm 4 \mathrm{~mm})$, most of the asperities remained intact after cyclic shear test. With increasing amplitude $( \pm 6 \mathrm{~mm})$, degradation of asperities was observed. For high displacement amplitude $( \pm 8 \mathrm{~mm})$, the degradation of asperities was significant. 


\section{Fig. 10 [Near here]}

\subsection{Shear Strength Envelope for Cyclic Shear Load}

Joints under cyclic shear load exhibit double peak shear stress for each cycle, i.e. one peak at the forward movement and another peak at the backward movement. Shear strength envelopes for different shear load frequencies and displacement amplitudes at forward and backward movements are presented in Fig. 11. The envelopes were plotted based on peak shear stress values in Figs. 4 and $5(\mathrm{P}=0.1 \mathrm{MPa})$ and Figs. $12-15(\mathrm{P}=0.5$ and $1 \mathrm{MPa})$ in appendix.

At the first cycle, shear strength envelope was curvilinear (Fig. 11a) and it rose with increasing load frequency (from 0.01 to $0.1 \mathrm{~Hz}$ ). The envelope was greater for the first forward movement compared to the first backward movement. For the backward movement the effect of frequency was negligible. For subsequent cycles, the envelope was linear (relatively) and no significant change was observed as the load frequency increased (Fig. 11b and c; Fig. 16a-c in appendix). Shear strength envelope was equal for varying displacement amplitudes $( \pm 4, \pm 6$, and $\pm 8 \mathrm{~mm})$ at the first forward movement (Fig. 11d). However, it was different for the first backward movement. For subsequent cycles, this difference between the envelopes was significant (Fig. 11e and f; Fig. 16d-f in appendix).

The opposite effect of load frequency and displacement amplitude was observed on the joint by comparing the envelopes. Shear strength envelope for varying frequencies was different at the first forward movement and it started to be similar from the first backward movement. However, shear strength envelope for varying amplitude was similar at the first forward movement and it started to be different from the first backward movement.

Fig. 11 [Near here]

\section{Conclusions}


A series of cyclic shear tests was conducted on soft synthetic rock joints. Varying load frequencies and displacement amplitudes for three different normal stresses were applied. Based on the experimental results, the following conclusions can be obtained:

1) The first peak shear stress on the joint is significantly influenced by the frequency of cyclic shear load and subsequent peaks of shear stress are largely influenced by the amplitude of displacement. Reduction in peak shear stress for higher frequency of load is greater than the reduction for lower frequency of load under cyclic movements.

2) Diminishing of asperities on the joint is equal at high frequency of shear loads under low normal stress for the both directions (forward and backward movements), i.e. shear mechanism on the joint asperities does not depend on load direction at high frequency. But at low frequency of loads, diminishing of asperities is unequal, i.e. shear mechanism depends on direction of starting cyclic shear load.

3) Low amplitude of displacement has no effect on asperities degradation under cyclic loads. Only sliding is dominating on the joint. As the amplitude rises, the diminishing of asperities increases significantly.

4) Shear mechanism and asperity diminishing is similar for the both higher amplitude of displacement and lower frequency of load at low normal stress. It is because of grater diminishing on the second slopes of asperities during cyclic movements. In consequence, failure on a rock joint is more expected in opposite to the direction of starting movement of cyclic load.

5) The joint exhibits an opposite behaviour at varying load frequencies and displacement amplitudes. Shear strength envelope for varying frequencies is different at the first forward movement and it starts to be similar from the first backward movement. Shear strength envelope 
for varying amplitude is similar at the first forward movement and it starts to be different from the first backward movement.

\section{References}

Atapour H, Moosavi M (2014) The influence of shearing velocity on shear behavior of artificial joints. Rock Mech Rock Eng 47(1):1745-61. https://doi.org/10.1007/s00603-013-0481-9

Barbero M, Barla G, Zaninetti A (1996) Dynamic shear strength of rock joints subjected to impulse loading. Int J Rock Mech Min Sci 33(2):141-151. https://doi.org/10.1016/01489062(95)00049-6

Barla G, Barbero M, Scavia C, Zaninetti A (1990) Direct shear testing of single joints under dynamic loading. In: Barton N, Stephansson O (eds) Rock Joints, Balkema, Rotterdam, pp 447454.

Barton N, Choubey V (1977) The shear strength of rock joints in theory and practice. Rock Mech 10(1):1-54. https://doi.org/10.1007/BF01261801

Crawford AM, Curran JH (1981) The influence of shearing velocity on the frictional resistance of rock discontinuities. Int J Rock Mech Min Sci 18(1):505-515. https://doi.org/10.1016/01489062(81)90514-3

Dearman WR, Baynes FJ, Irfan TY (1978) Engineering grading of weathered granite. Eng Geol 12: 345-374. https://doi.org/10.1016/0013-7952(78)90018-2

Ferrero AM, Migliazza MR, Tebaldi G (2010) Development of a new experimental apparatus for the study of the mechanical behaviour of a rock discontinuity under monotonic and cyclic loads. Rock Mech Rock Eng 43(6):685-695. https://doi.org/10.1007/s00603-010-0111-8 
Gillette DR, Sture S, Ko HK, Gould M, Scott G (1983) Dynamic behavior of rock joints. Proceedings of the 24th US Symposium on Rock Mechanics, Texas, pp 163-79.

Guansheng H, Hongwen J, Yujing J, Richeng L, Jiangyu W (2020) Effect of cyclic loading on the shear behaviours of both unfilled and infilled rough rock joints under constant normal stiffness conditions. Rock Mech Rock Eng 53(1):31-57. https://doi.org/10.1007/s00603-01901866-w

Hassani FP, Scoble M J (1985) Frictional mechanism and properties of rock discontinuities. Proceedings of the Symposium on Fundamental of Rock Joints, Bjorkliden, pp 185-196

Hencher SR (1981) Friction parameters for the design of rock slopes to withstand earthquake loading. Proceedings of the Conference in Dams and Earthquake, pp 79-87. https://doi.org/10.1680/dae.01237.0012

Homand-Etienne F, Lefe^vre F, Belem T, Souley M (1999) Rock joints behaviour under cyclic direct shear tests. Proceedings of the 37th US Symposium on Rock Mechanics, Colorado pp 399-406

Huang X, Haimson B, Plesha ME, Qiu X (1993) An Investigation of the Mechanics of Rock Joints. Int J Rock Mech Min Sci 30(3): 257-269. https://doi.org/10.1016/0148-9062(93)92729-A Hutson RW, Dowding CH (1990) Joint asperity degradation during cyclic shear. In J Rock Mech Min Sci 27(2):109-119. https://doi.org/10.1016/0148-9062(90)94859-R

Yang J, Cai J, Yao C, Li P, Jiang Q, Zhou C (2019) Comparative study of tunnel blast-induced vibration on tunnel surfaces and inside surrounding rock. Rock Mech Rock Eng 52(11):47474761. https://doi.org/10.1007/s00603-019-01875-9. 
Jafari MK, Hosseini Amini K, Pellet F, Boulon M, Buzzi O (2003) Evaluation of shear strength of rock joints subjected to cyclic loading. Int J Soil Dyn Earth Eng 23(7):619-630. https://doi:10.1016/S0267-7261(03)00063-0

Jing L, Stephansson O, Nordlund E, (1993) Study of rock joints under cyclic loading conditions Rock Mech Rock Eng 26(3):215-232. https://doi.org/10.1007/BF01040116

Lee HS, Park YJ, Cho TF, You KH (2001) Influence of asperity degradation on the mechanical behavior of rough rock joints under cyclic shear loading. Int J Rock Mech Min Sci 38(7):967980. https://doi.org/10.1016/S1365-1609(01)00060-0

Mirzaghorbanali A, Nemcik J, Aziz N (2014) Effects of shear rate on cyclic loading shear behaviour of rock joints under constant normal stiffness conditions. Rock Mech Rock Eng 47(5): 1931-1938. https://doi.org/10.1007/s00603-013-0453-0

Nemcik j, Mirzaghorbanali A, Aziz N (2013). An elasto-plastic constitutive model for rock joints under cyclic loading and constant normal stiffness. Geotech Geol Eng 32(2):321-335 https://doi.org/10.1007/s10706-013-9716-5.

Niktabar SMM, Rao KS, Shrivastava AK (2017) Effect of rock joint roughness on its cyclic shear behavior. Rock Mech Geotech Eng 9(6):1071-1084. https://doi.org/10.1016/j.jrmge.2017.09.001

Niktabar SMM, Rao KS, Shrivastava AK (2018) Automatic static and cyclic shear testing machine under constant normal stiffness boundary conditions. Geotech Testing J 41(3):508-525. https://doi.org/10.1520/GTJ20170083.

Nguyen VM (2013) Static and dynamic behaviour of joints in schistose rock. Dissertation, University of Bergakademie Freiberg 
Nkpadobi JI, Raj JK, Ng TF (2015) Failure mechanisms in weathered meta-sedimentary rocks Environ Earth Sci 73:4405-4418. https://doi.org/10.1007/s12665-014-3725-4

Qiu X, Plesha ME, Huang X, Haimson B (1993) An investigation of the mechanics of rock joints. Part II-analytical investigation. Int J Rock Mech Min Sci 30:271-287. https://doi.org/10.1016/0148-9062(93)92730-E.

Richards LR (1975) Shear strength of joints in weathered rocks. Dissertation, Imperial College of Science and Technology

Ram BK, Basu A (2019) Shear behavior of unfilled-planar quartzitic rock joints with reference to weathering grade of joint surfaces. Rock Mech Rock Eng 52:4113-4121. https://doi.org/10.1007/s00603-019-01815-7.

Ramulu M, Chakraborty A, Sitharam T (2009) Damage assessment of basaltic rock mass due to repeated blasting in a railway tunnelling project—a case study. Tunn Undergr Space Technol 24(2):208-221. https://doi:10.1016/j.tust.2008.08.002

Schneider HJ (1977) The time dependence of friction of rock joints. Bull Eng Geol Environ 16:235-239.

Tang ZC, Wong LNY (2016) Influences of normal loading rate and shear velocity on the shear behavior of artificial rock joints. Rock Mech Rock Eng 49(6):2165-2172. https://doi.org/10.1007/s00603-015$0822-\mathrm{y}$

Wu XZ, Jiang YJ, Gong B, Guan ZC, Deng T (2019) Shear performance of rock joint reinforced by fully encapsulated rock bolt under cyclic loading condition. Rock Mech Rock Eng 52:2681-2690 https://doi.org/10.1007/s00603-018-1698-4.

Yan X, Xu B, Zhang L. et al. (2019) Mechanism analysis of a landslide in highly weathered volcanic rocks of Niushoushan Hill in Nanjing. Environ Earth Sci 78:676. https://doi.org/10.1007/s12665-0198705-2 


\section{Statements and Declarations}

There are no conflicts of interest to declare and we believe that the manuscript and the study, none of them violate journal's policies. All authors have seen the manuscript and they have approved its submission to your journal. 


\section{Figures}
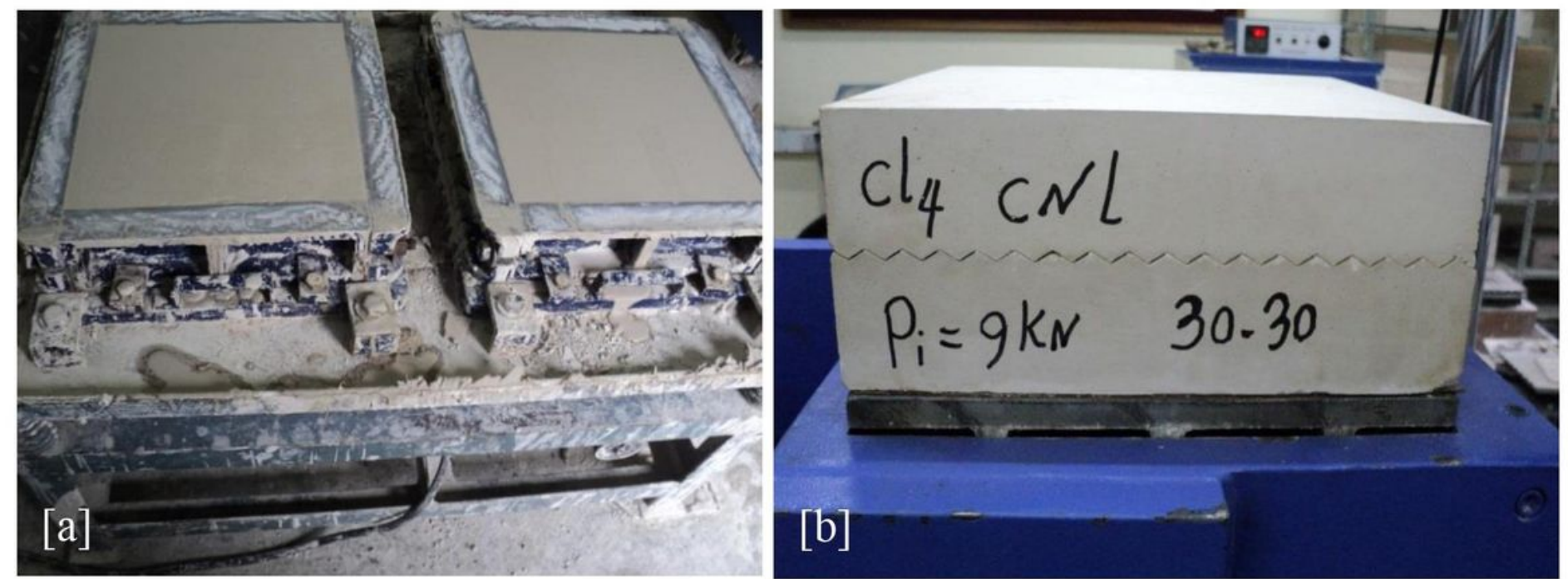

Fig. 1 Moulds fixed on the vibration table during specimen preparation (a) and prepared $30^{\circ}-30^{\circ}$ joint asperity (b)

\section{Figure 1}

Please See image above for figure legend. 


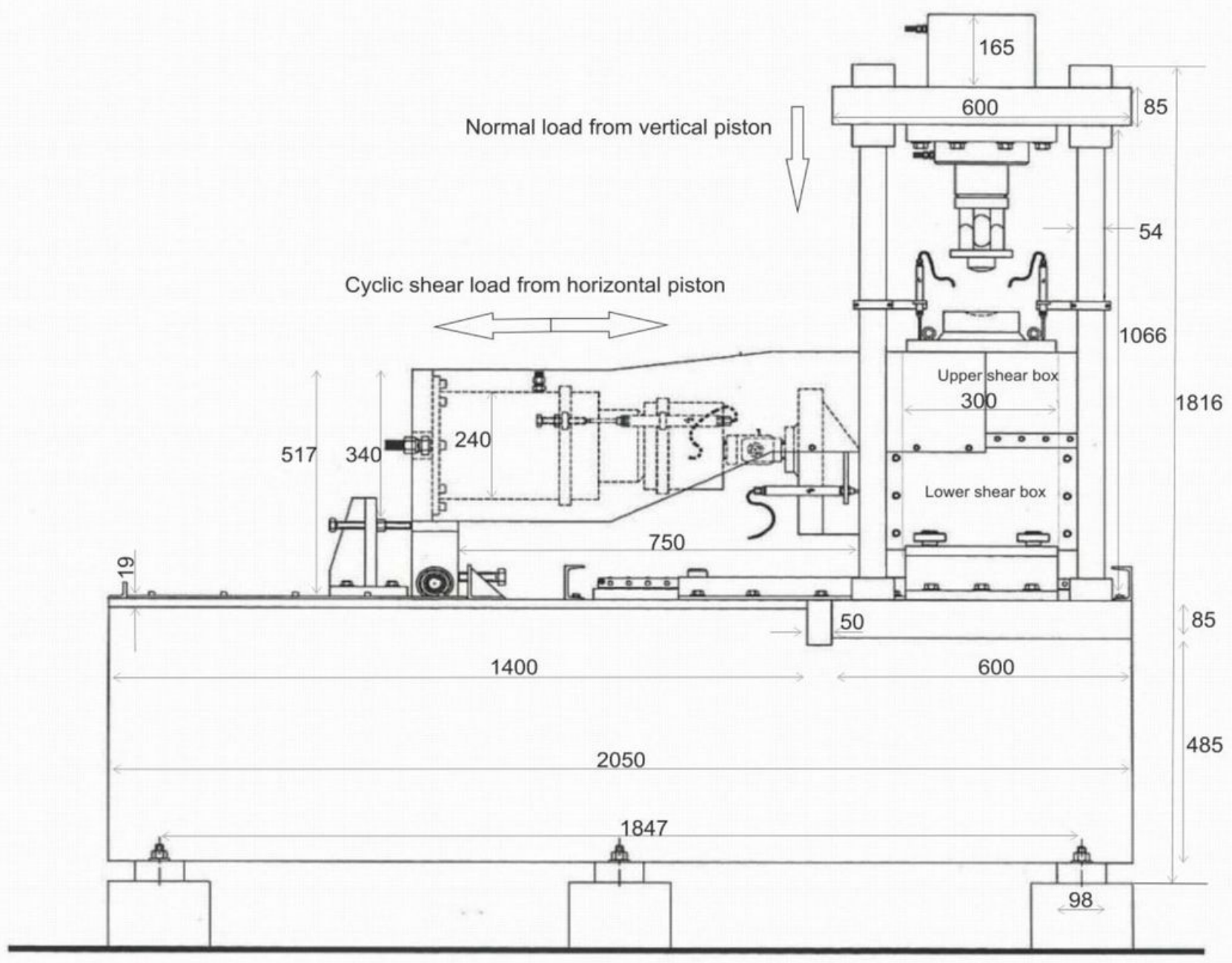

Fig. 2 Diagrams of the large scale shear testing machine (all dimensions in $\mathrm{mm}$ )

Figure 2

Please See image above for figure legend. 


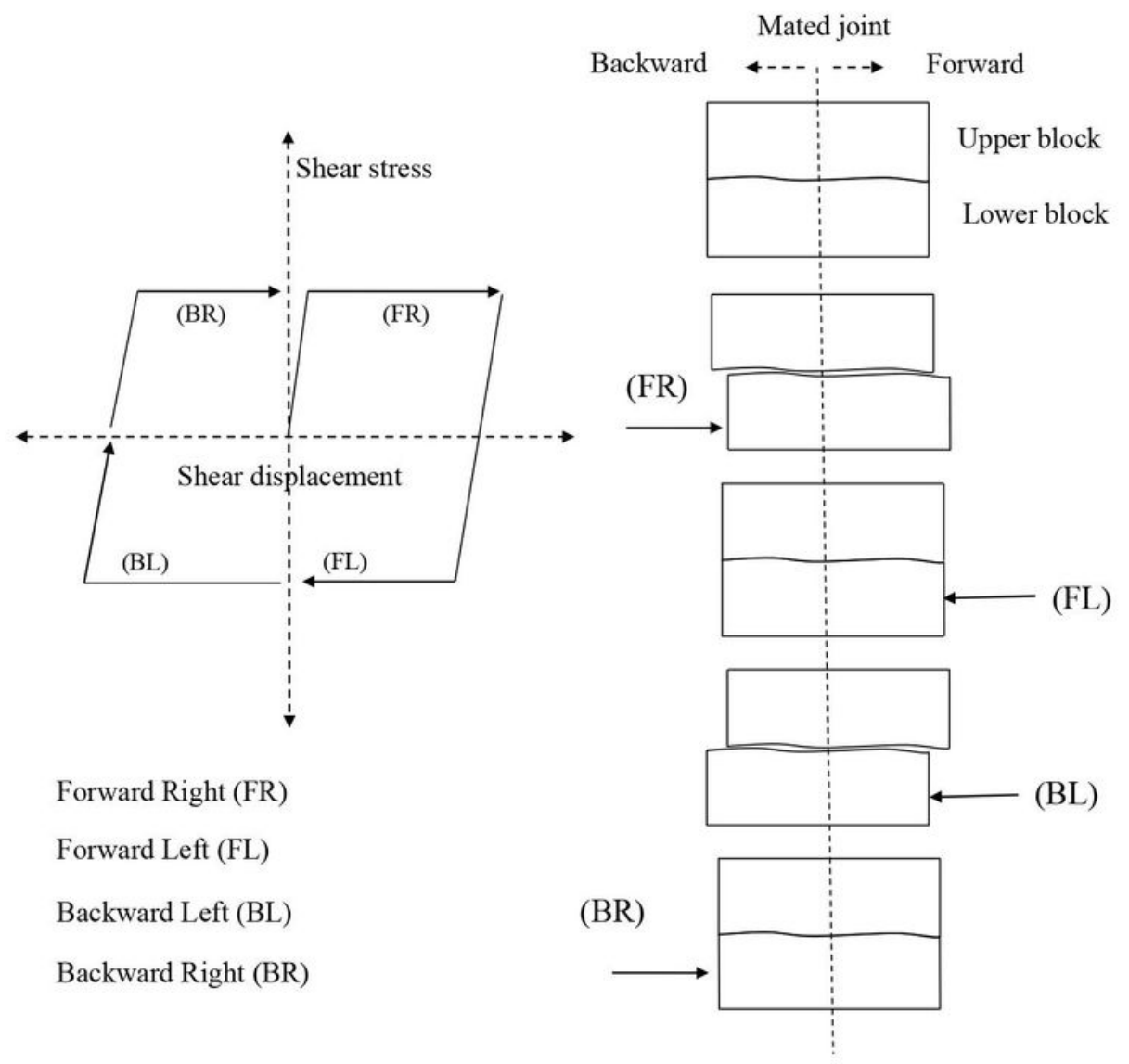

Fig. 3 Cyclic shear load on the joint with the both forward and backward movements (Niktabar et al. 2017)

\section{Figure 3}

Please See image above for figure legend. 


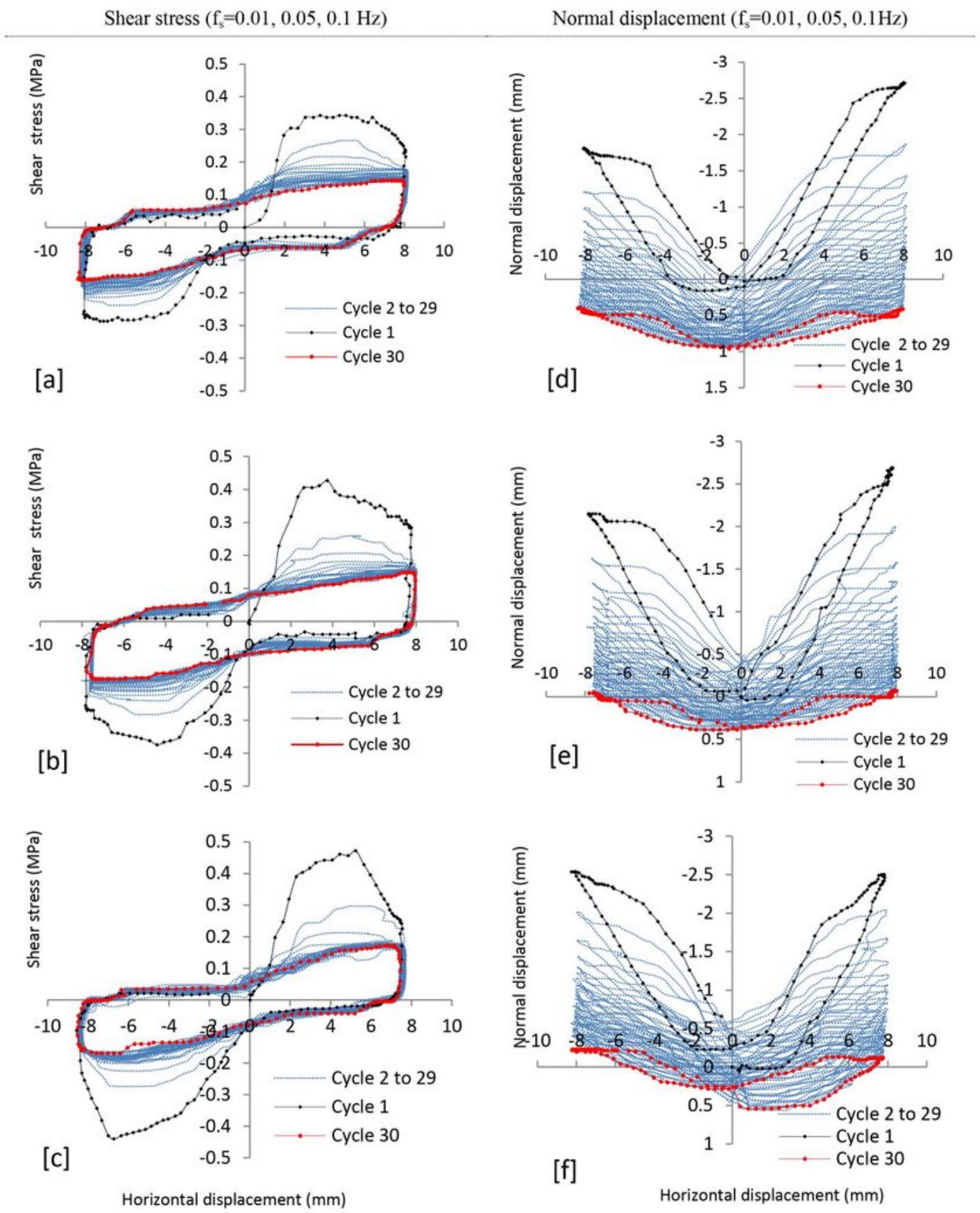

Fig. 4 Shear stress and normal displacement vs. horizontal displacement of the joint for cyclic shear load with different frequencies, $\mathrm{f}_{\mathrm{s}}=0.01,0.05$ and $0.1 \mathrm{~Hz}$ respectively $(\mathrm{P}=0.1 \mathrm{MPa})$

\section{Figure 4}

Please See image above for figure legend. 


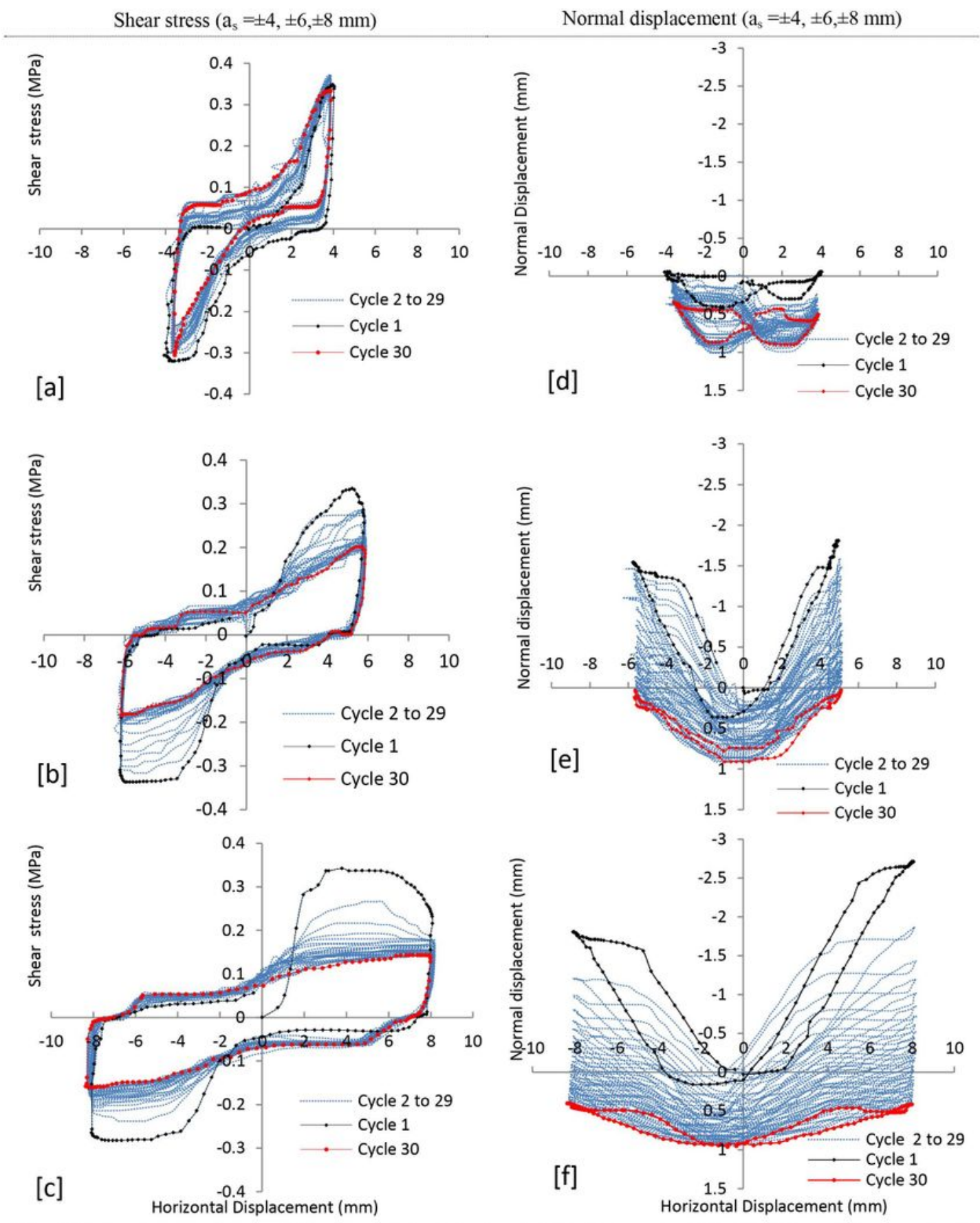

Fig. 5 Shear stress and normal displacement vs. horizontal displacement of the joint for cyclic shear load with different amplitudes, $\mathrm{a}_{\mathrm{s}}=4,6$ and $8 \mathrm{~mm}$ respectively $(\mathrm{P}=0.1 \mathrm{MPa})$

\section{Figure 5}

Please See image above for figure legend. 
Peak shear stress, $\left(\mathrm{f}_{\mathrm{s}}=0.01,0.05,0.1 \mathrm{~Hz}\right)$
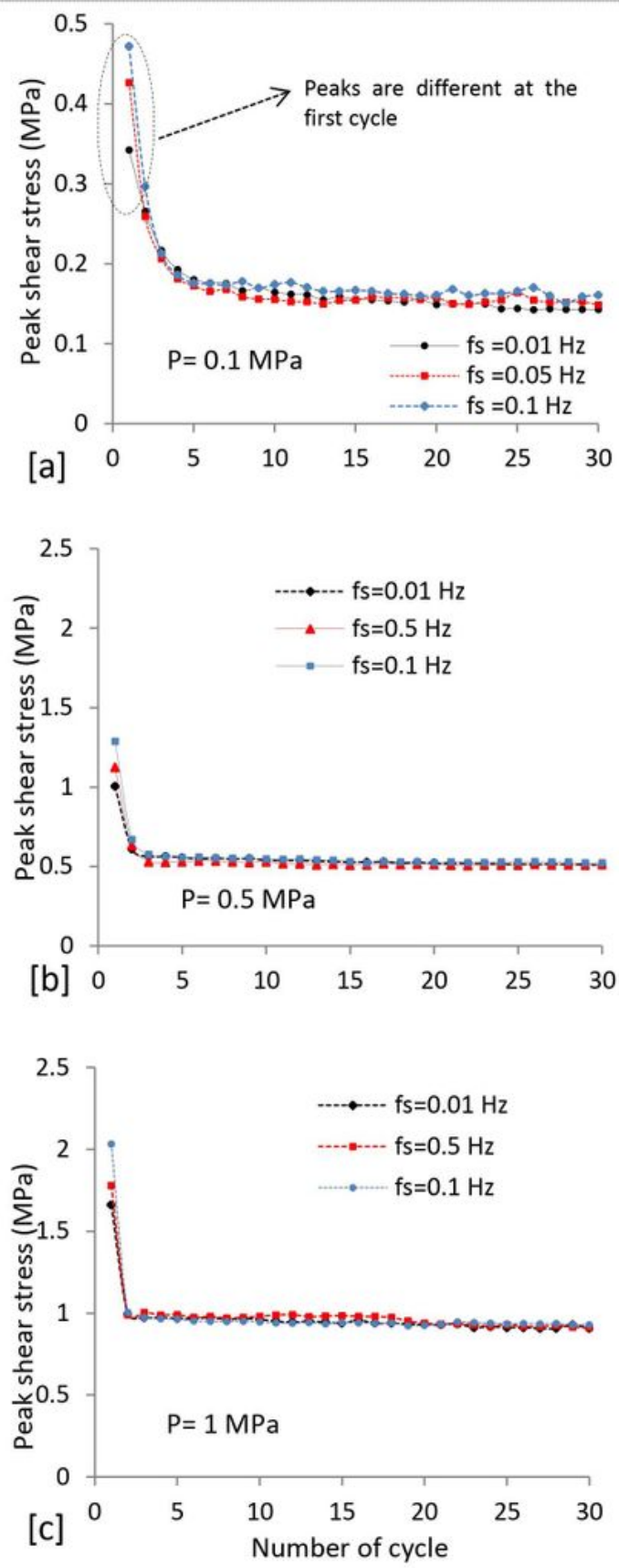

Peak shear stress, $\left(a_{\mathrm{s}}= \pm 4, \pm 6, \pm 8 \mathrm{~mm}\right)$
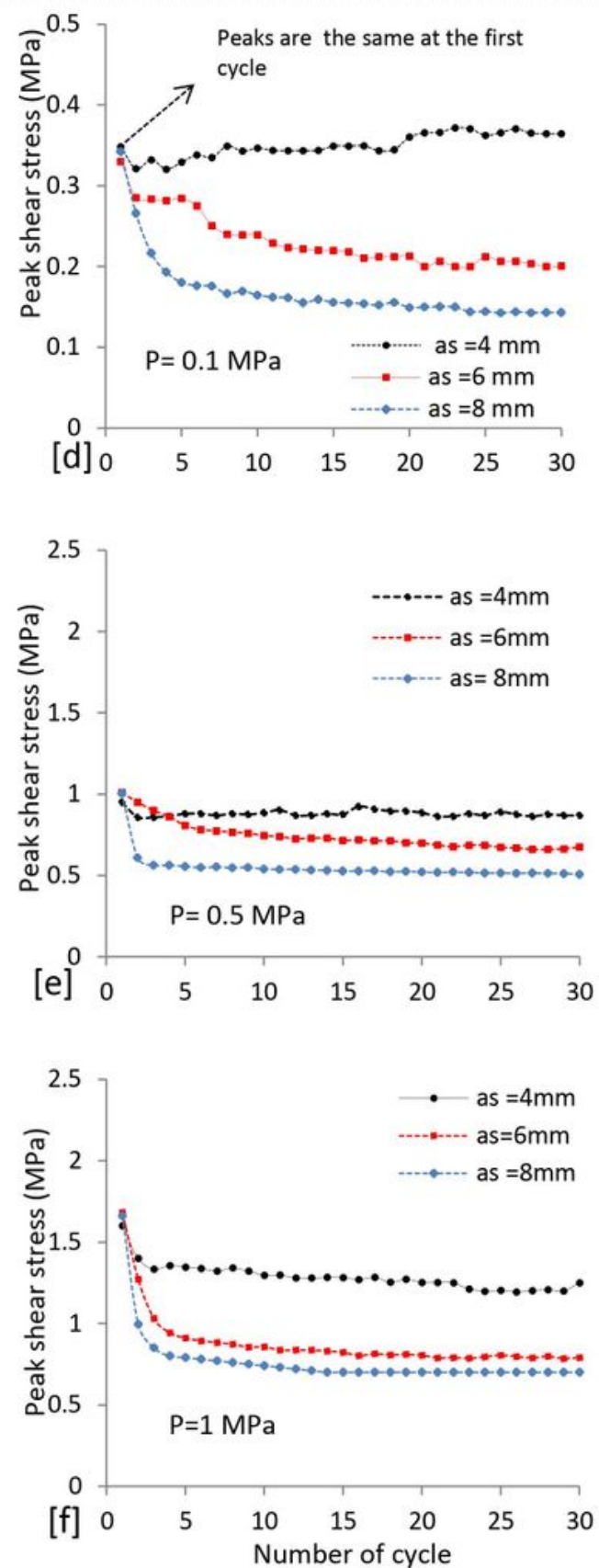

Fig. 6 Peak shear stress vs. number of cycles under varying load frequencies $\left(\mathrm{f}_{\mathrm{s}}=0.01,0.05,0.1 \mathrm{~Hz}\right)$ and amplitudes of displacement $\left(\mathrm{a}_{\mathrm{s}}= \pm 4, \pm 6, \pm 8 \mathrm{~mm}\right)$ on the joint for $\mathrm{P}=0.1,0.5$ and $1 \mathrm{MPa}$ respectively

\section{Figure 6}

Please See image above for figure legend. 

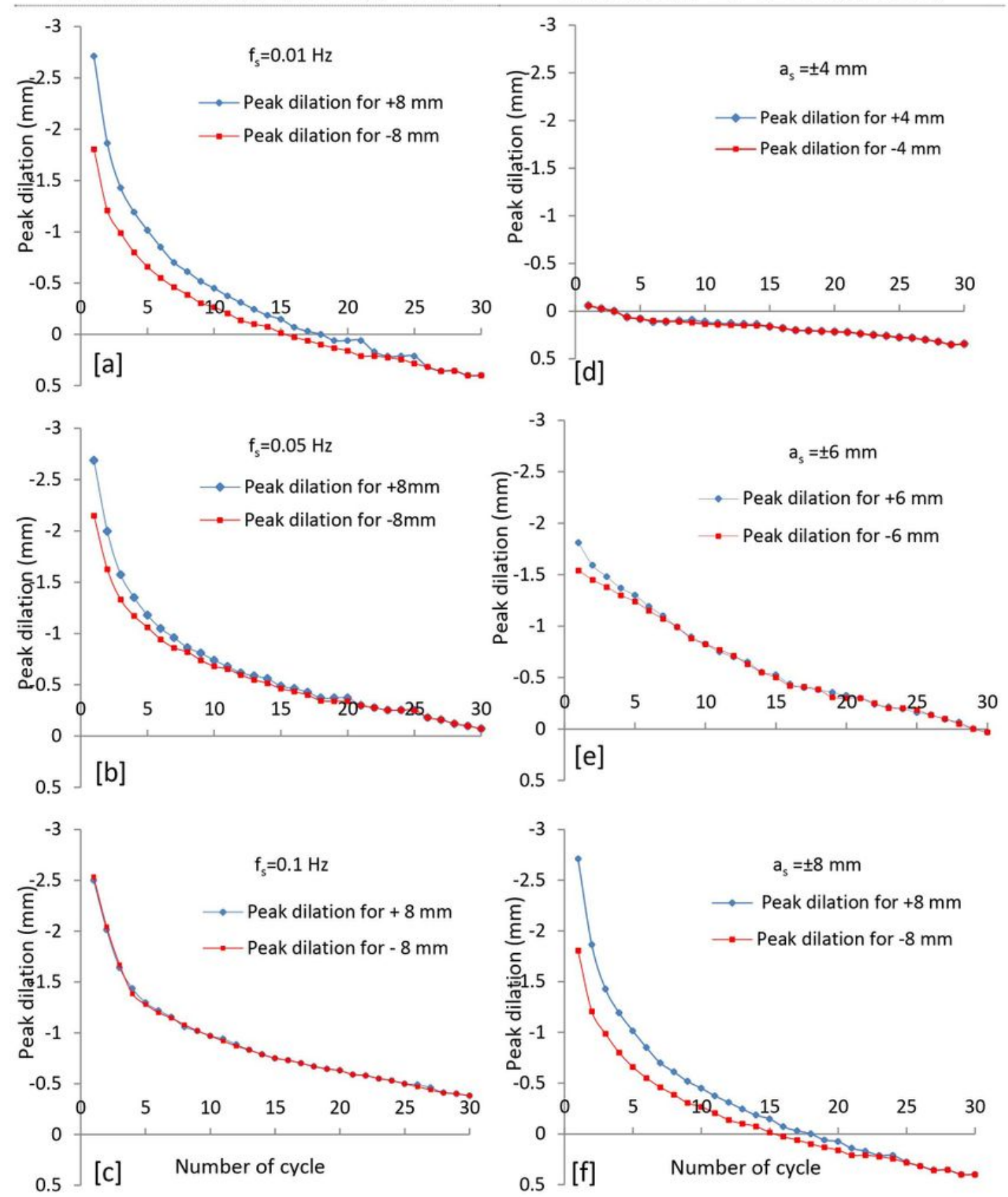

Fig. 7 Peak dilation vs. number of cycles under varying load frequencies $\left(f_{s}=0.01,0.05,0.1 \mathrm{~Hz}\right)$ and different amplitudes of displacement $\left(\mathrm{a}_{\mathrm{s}}= \pm 4, \pm 6, \pm 8 \mathrm{~mm}\right)$ on the joint for $\mathrm{P}=0.1 \mathrm{MPa}$ respectively

\section{Figure 7}

Please See image above for figure legend. 
Different diminishing on the slopes involved in cyclic shear

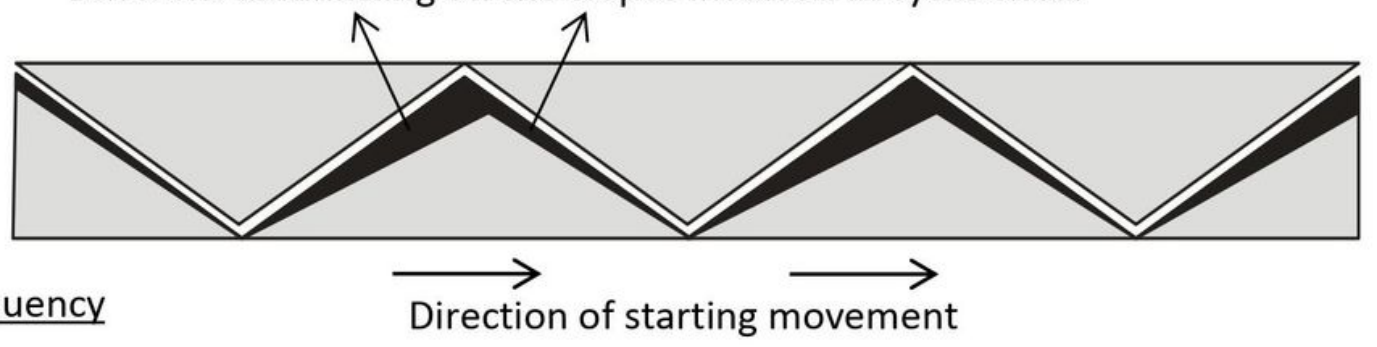

(a) Low frequency

Direction of starting movement

Equal diminishing on the slopes involved in cyclic shear

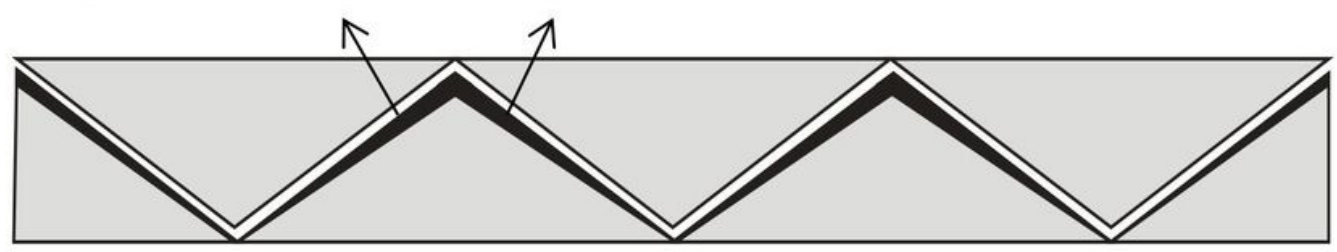

(b) High frequency

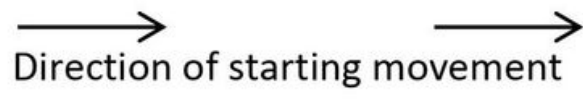

Fig. 8 Asperity diminishing on the joint for low (a) and high (b) shear load frequency under cyclic movements $(\mathrm{P}=0.1 \mathrm{MPa})$

\section{Figure 8}

Please See image above for figure legend. 
No significant diminishing on the both slopes involved in cyclic shear

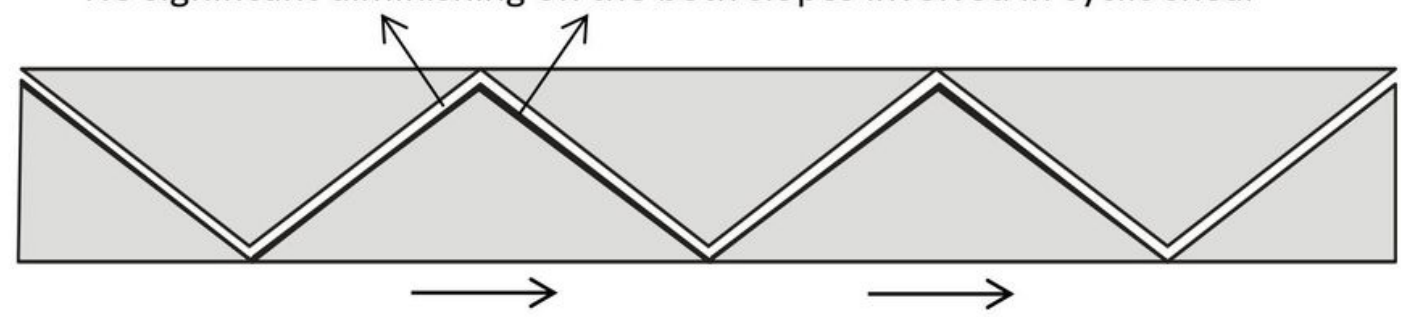

(a) Low amplitude Direction of starting movement

Different diminishing on the slopes involved in cyclic shear

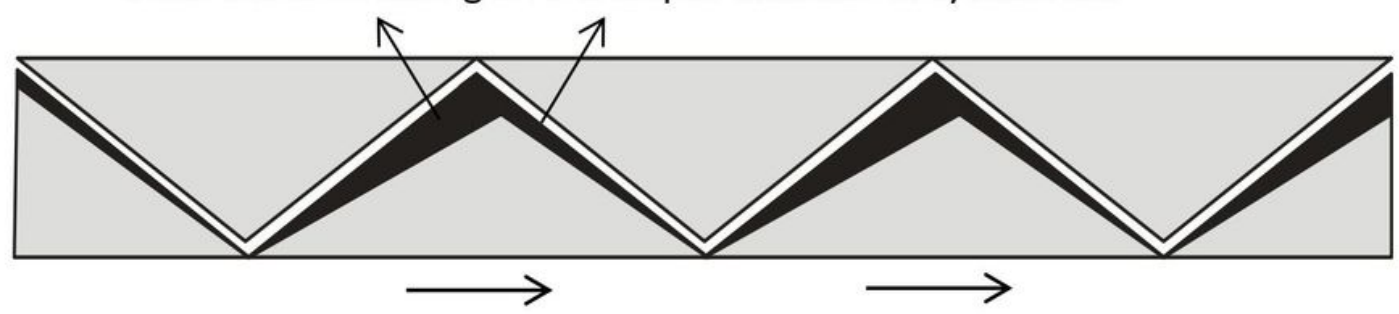

(b) High amplitude Direction of starting movement

Fig. 9 Asperities diminishing on the joint for low (a) and high (b) amplitude of displacement under cyclic movements $(\mathrm{P}=0.1 \mathrm{MPa})$

\section{Figure 9}

Please See image above for figure legend. 

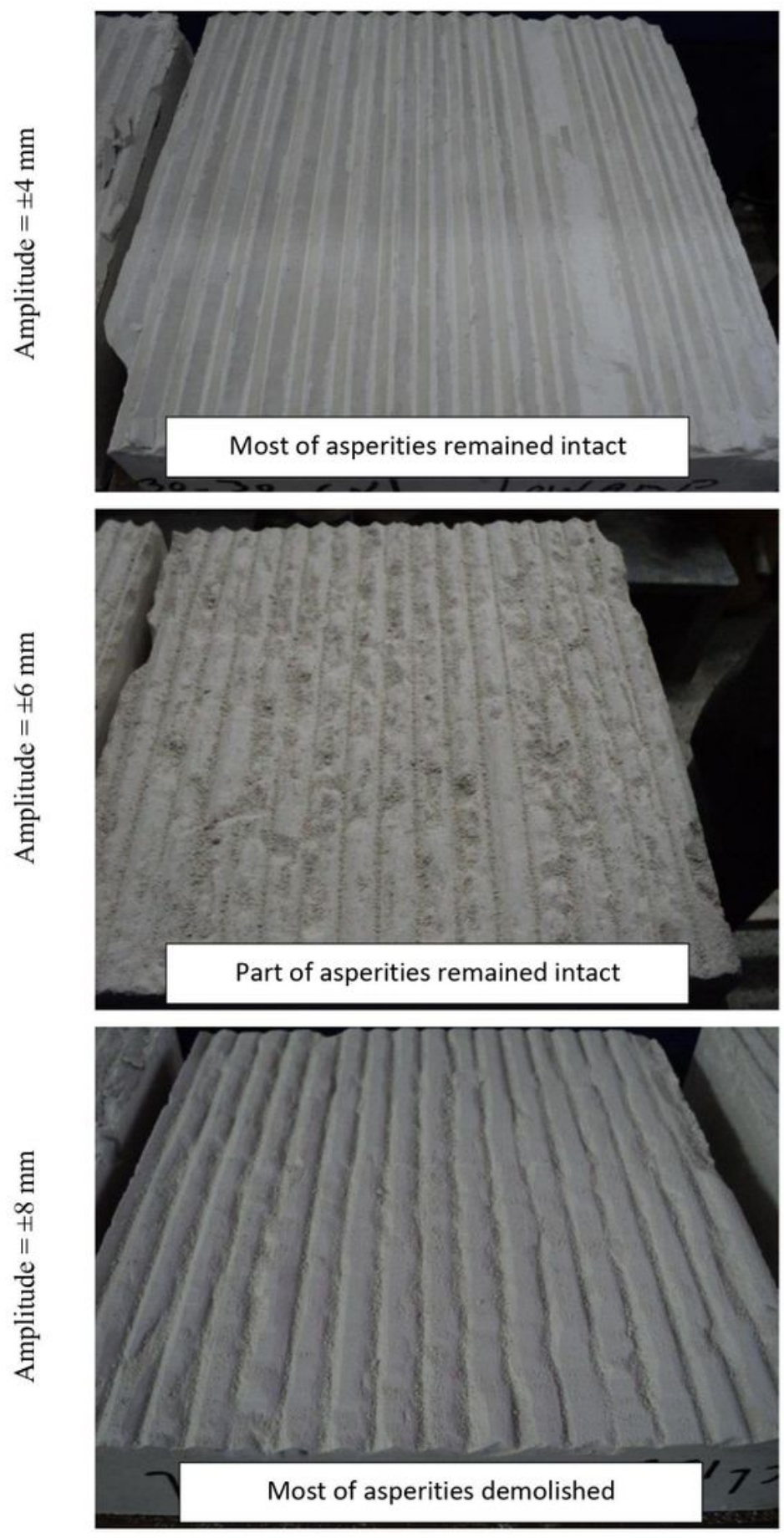

Fig. 10 Joint with $30^{\circ}-30^{\circ}$ asperity after 30 shear cycles for different displacement amplitude, $\mathrm{P}=0.1 \mathrm{MPa}$

\section{Figure 10}

Please See image above for figure legend. 


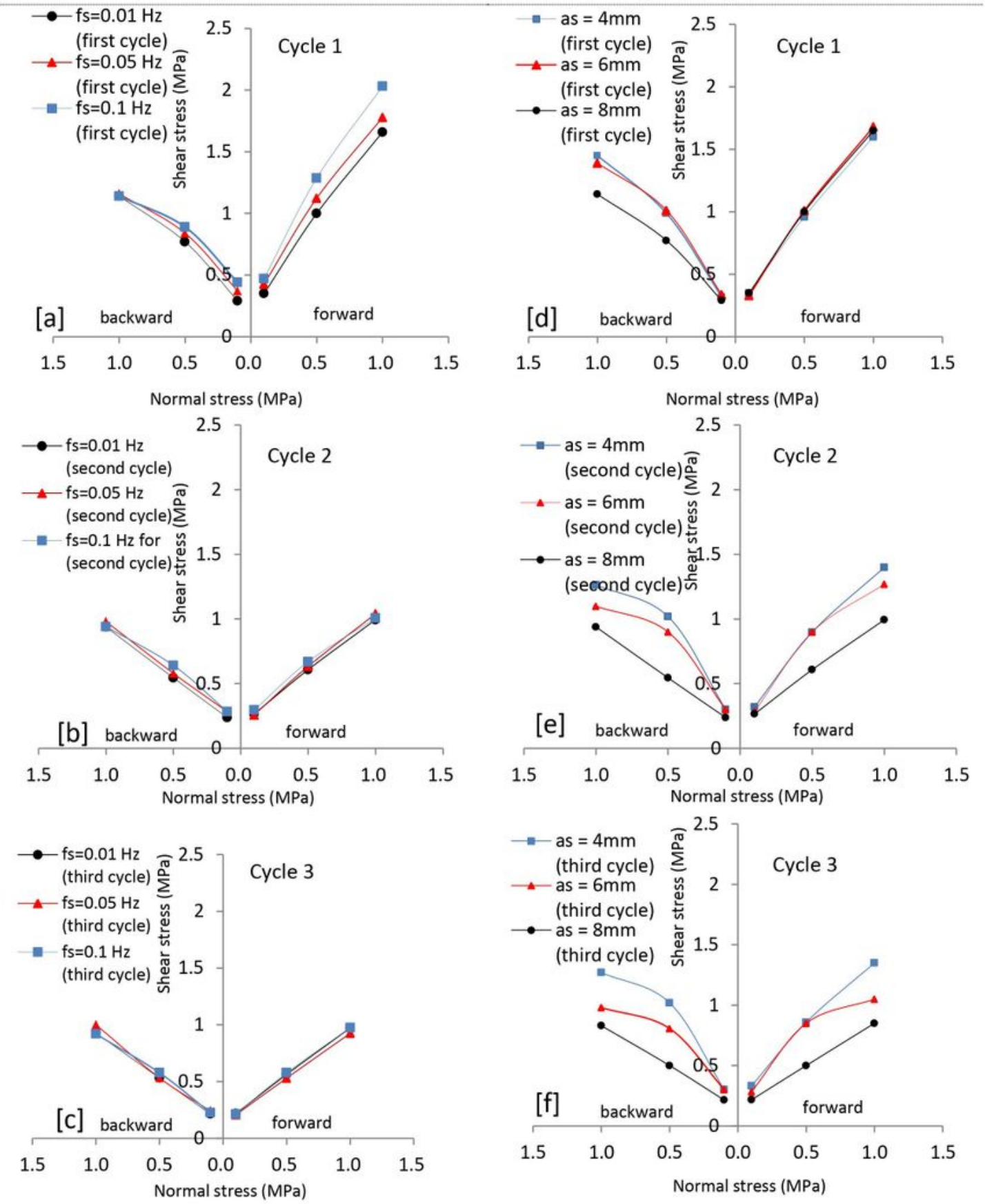

Fig. 11 Shear strength envelope of $30^{\circ}-30^{\circ}$ joint under varying shear load frequencies $\left(\mathrm{f}_{\mathrm{s}}=0.01,0.05,0.1\right.$ $\mathrm{Hz})$ and amplitudes of displacement $\left(\mathrm{a}_{\mathrm{s}}= \pm 4, \pm 6, \pm 8 \mathrm{~mm}\right)$ for three different cycles respectively

\section{Figure 11}

Please See image above for figure legend.

\section{Supplementary Files}


This is a list of supplementary files associated with this preprint. Click to download.

- Table13.pdf

- AppendixFig.14.pdf

- AppendixFig.15.pdf

- AppendixFig.16.pdf

- Appendix.Fig12.pdf

- Appendix.Fig.13.pdf 